\title{
A Cost Effective Energy Saving of Fluorescent Lighting in Commercial Buildings
}

\author{
Seong-Ryong Lee ${ }^{\dagger}$ and Chemmangot V. Nayar* \\ $\dagger$ Dept. of Control and Robot Eng., Kunsan National University, Kunsan, Korea \\ ${ }^{*}$ Dept. of Electrical and Computer Eng., Curtin University of Technology, Perth, Australia
}

\begin{abstract}
Lighting represents a significant component of commercial buildings, particularly office buildings. Fluorescent lighting is invariably used in all commercial, industrial and residential areas. A significant amount of lighting energy is wasted every day by leaving the lights on and not utilizing daylight energy. However, if daylight illuminance can be harnessed, this will reduce the electricity consumption of fluorescent lamps and save energy. This paper explains possible significant savings in lighting energy consumption and hence in costs, without reducing the performance and visual satisfaction in office or industrial buildings. It is proposed to obtain energy saving by reducing the supply voltage without degradation in lighting performance. Experimental results confirm that as much as $20 \%$ of electrical energy can be saved by reducing about $9 \%$ of the supply voltage, without noticeably affecting light output while complying with lighting standard limits.
\end{abstract}

Key Words: Commercial Building, Commercial Energy Saving, Energy Saving, Fluorescent Lamp

\section{INTRODUCTION}

Light plays an important role in our daily life. It is extensively used, not only at night but also in the daytime in most office and industrial buildings. Lighting consumes the largest portion of electricity used in most commercial buildings and hence there is a potential for considerable energy saving. Records show that lighting dominates energy consumption. For instance, it consumes $40 \%$ of the total electrical energy in commercial buildings and about $9 \%$ in industrial plants [1]. In particular, fluorescent lighting (FL) consumes about $20 \%$ of total lighting consumption [2]. Fluorescent lighting is invariably used in all commercial, industrial and residential areas [3]-[8]. Nevertheless, most of the time a significant amount of energy is wasted through inefficient behaviour such as leaving lights on by occupants. Moreover, daylight energy is not used to reduce electricity consumption. Given the above, there is a strong possibility of saving energy in commercial and industrial buildings.

Fluorescent lamps have been shown to be the most efficient, cost effective and long lasting lighting device. They produce less heat, shadow and are able to provide better luminance than other types of lamps [9], [10].

Two conventional technologies for efficient FL in conjunction with energy saving have been proposed. They can

Manuscript received May 20, 2011; revised Oct. 7, 2011

Recommended for publication by Associate Editor Tae-Woong Kim.

$\dagger$ Corresponding Author: srlee@ kunsan.ac.kr

Tel: +82-63-469-4703, Fax: +82-63-469-4699, Kunsan Nat'l Univ.

* Dept. of Electrical and Computer Eng., Curtin University of Technology, Australia generally be classified as follows [11]-[13]:

- Minimizing hours usage - Control System (dimming, scheduling) and daylight harvesting. It benefits from three different control methods including manual, automatic and computer or microprocessor based.

- Minimizing installed power - Retrofitting or efficiently compensating the lighting due to lumen depreciation, i.e. developing a high efficiency lamp and ballast.

Though these methods contribute to energy saving, they suffer from disadvantages such as high labour costs, the replacement cost of lamps and fittings and longer time to implement. Sunlight cannot always make a significant contribution to the interior lighting. An increase in sunlight will also heat up the offices and increase the air-conditioners' load. Furthermore, sunlight intensity is fairly unreliable due to cloudy days or even after dark. To overcome the situation, this paper presents an analytical model to assist in the understanding of light energy saving in fluorescent lamps, regardless of the building's structure. It is proposed to reduce the supply voltage to a certain acceptable level, which will not degrade the performance of the lighting system below the recommended luminous flux. The proposed idea works not only for artificial lighting, but will be further improved if sunlight is incorporated to provide enough luminous flux as recommended.

\section{Lighting In COMMERCIAL BUILDingS}

\section{A. Daylight}

Daylight is the sum of sunlight and skylight (Fig. 1), where sunlight is the light directly produced by the sun and skylight 


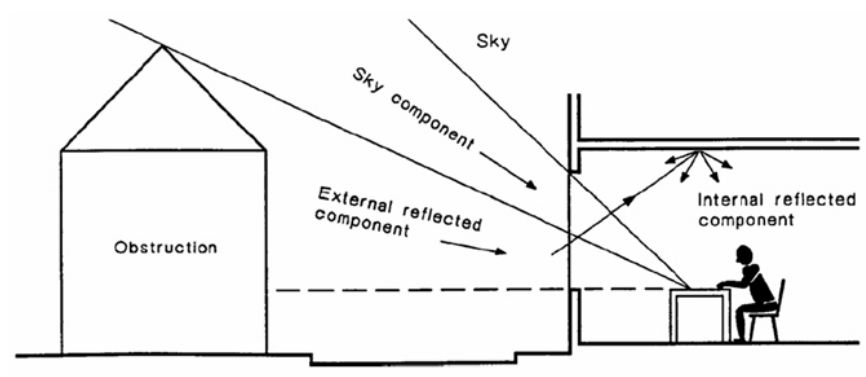

Fig. 1. The components of daylight that contribute to the illuminance at a point in a room [13].

is the light diffused and scattered by the earth's atmosphere. Daylight can be used to illuminate interiors. This luminance varies with the sun's motions and atmospheric conditions. The luminance is predictable for sunny days and can be used as a complimentary source for internal lighting. However, due to changes in atmospheric conditions without automatic feedback control (using photocells), it is not possible to use this available daily energy effectively and hence save lighting energy.

\section{B. Design Considerations}

To design an interior, one of the three following approaches will generally be chosen [13]: 1) to rely on daylight during daytime and to design electric lighting only for night-time, 2) to use the daylight available as a supplementary component to electric lighting, or 3) to ignore daylight and operate the building solely on electric lighting. The third method is the most conservative approach which is generally selected to design the interior of commercial buildings.

The efficiency of lamp and luminaire (miscellaneous equipment necessary for operating the lamp, e.g. reflector, ballast, etc.) combination, when used to provide uniform lighting in a room is expressed by the utilization factor (UF). Fig. 2 illustrates the effect of maintenance strategies on lamp luminance as a function of time. It shows just the lamp lumen depreciation could drop in the luminance equivalent to curve A. Moreover a thin layer of dust on all room surfaces is another factor in the drop of the luminance (curve B). In addition, dirt on the lamp and luminaire is another important factor affecting the luminance and is a function of time (curve C). If lamps are maintained at regular intervals with cleaning and relamp it is possible to maintain the required luminance in the room as is shown in Fig. 2. it is required to define the Maintenance Factor (MF) for each room to calculate the number of the FLs. MF can be calculated as follows [14]:

$$
M F=L L M F \times L S F \times L M F \times R S M F .
$$

Where LLMF is lamp lumen maintenance factor, LSF is lamp survival factor, LMF is luminaire maintenance factor and RSMF is room surface maintenance factor.

The MF at the end of maintenance cycle is used to determine the required initial lamp flux based on the desired maintenance illuminance $\left(E_{m}\right)$, hence, the number of luminaires needed can be determined.

$$
E_{m}=\frac{\phi_{i} \times N \times U F \times M F}{A} .
$$

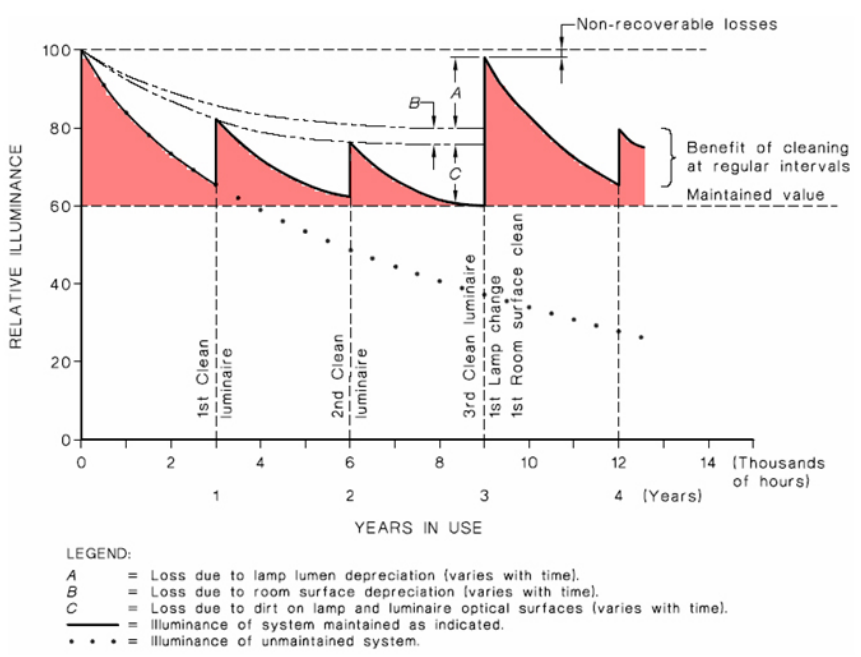

Fig. 2. Maintenance strategies' effect on luminance with time [14].

Where $\phi_{i}$ is the initial luminous flux of the FLs, $\mathrm{N}$ the number of lamps, A is the area to be illuminated.

\section{Potential of Light Energy Saving}

There are considerable amounts of possible energy saving during the life of the FLs considering the two main following factors.

First, including daylight for internal illuminance while reducing the amount of heat coming into the rooms from windows, this causes over loading and hence increases electricity consumption by air-conditioning systems. In this case, the excess illuminance from windows can be used to reduce the illuminance from the luminaries (FLs) by reducing the FLs' luminance by reducing the input voltage as explained in the next section.

Second, Fig. 2 and (2) show the need to provide more FLs initially to ensure compliance with the minimum illuminance at all times through the maintenance cycle. Therefore at the beginning of the lamps' life more illuminance is available (painted area in Fig. 2). This can be reduced over time to the necessary level of maintenance illuminance $\left(E_{m}\right)$ by reducing the input voltage of luminaires.

\section{REVIEW OF FLUORESCENT LIGHTING}

\section{A. Characteristics of a Fluorescent Lamp}

A simplified diagram of a fluorescent lamp with electromagnetic ballast is shown in Fig. 3. Fluorescent lamps, which belong to the electric discharge lamps family, have negative resistance characteristics. Because of this negative resistance characteristic, fluorescent lamps will draw excessive current that may cause instant lamp destruction if operated directly from the line voltage [15], [16]. A series electromagnetic ballast (EM) is needed to provide the proper starting and operating voltage and later limit the current in order to initiate and maintain the arc discharge between the two electrodes of the lamp. The lamp current $\left(\mathrm{i}_{a}\right)$ and voltage (Va) possess nonlinear characteristics [9], [15], [16]. There are two types of commonly used ballasts; the electromagnetic ballast and the electronic ballast. Although electronic ballasts are in great 


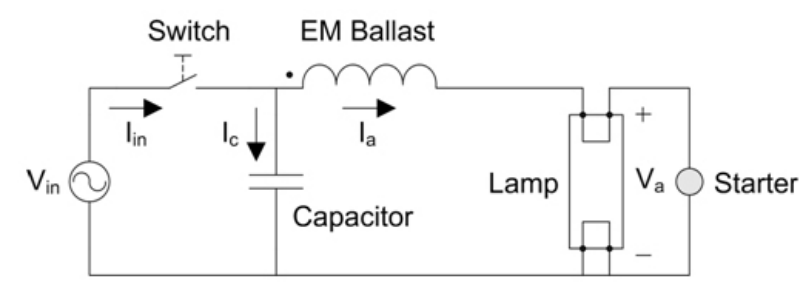

Fig. 3. The electric circuit diagram of a FL with electromagnetic ballast.

demand nowadays, the electromagnetic ballast is still the most commonly used due to its low cost and simple design [17].

\section{B. Modelling and Analysis of a Fluorescent Lamp}

Electromagnetic ballasts are usually available as ResistiveInductive (RL), Inductive-Capacitive (LC) and only Inductive (L) ballasts. This paper focuses on the $\mathrm{L}$ ballast model, due to its wide use. The inductive ballast draws reactive current from the supply. To estimate the appropriate reduced supply voltage and its effect on lighting performance, the modelling and analysis of a fluorescent lamp with electromagnetic ballast will be presented. Fig. 3 shows the electric circuit diagram of a FL with electromagnetic ballast. To improve the power factor, a capacitor is connected in parallel to the source. Assuming that the input voltage (Vin) is sinusoidal, it can be shown as (3):

$$
v_{\text {in }}=V_{\text {in }} \sin (\omega t+\gamma)
$$

Where Vin represents the amplitude of the sinewave, gamma $\gamma$ is the phase difference between the lamp voltage (Va) with respect to the input voltage (Vin). The voltage across the FL (Va) can be approximated as a square wave (4).

$$
v_{a}=\frac{4 V_{a}}{\pi} \sum_{n=o d d} \frac{1}{n} \sin n \omega t
$$

Where Va represents the amplitude of the square wave. Although the lamp voltage can be approximated as a square wave, Va remains nearly constant during each half cycle, which can be simplified to a constant value. In contrast with the lamp current, Va can be assumed to be independent of the input voltage variations [15]. Hence the voltage drop across the ballast can be expressed as (5):

$$
v_{L}=L \frac{d i_{a}}{d t}=v_{\text {in }}(t)-v_{a}(t) .
$$

By integrating equation $(5), \mathrm{i}_{a}(\mathrm{t})$ can be found:

$$
i_{a}(t)=\frac{V_{a}}{\omega L}\left(\frac{\pi}{2}-\omega t\right)-\frac{V_{i n}}{\omega L} \cos (\omega t+\gamma) .
$$

The angle $\gamma$ can be found from the boundary conditions known, which is $i_{a}(0)=i_{a}(\pi)=0$, where $\gamma=$ $\cos ^{-1}\left(V_{a} \pi / 2 V_{\text {in }}\right)$.

Fig. 4 shows the lamp voltages with respect to the three different input voltages. This figure shows when the supply voltage decreases from $240 \mathrm{~V}$ (Australian standard voltage) to $180 \mathrm{~V}$, the phase angle also decreases from $\gamma_{1}$ to $\gamma_{3}$. This implies that the system power factor can improve while the input voltage reduces. Fig. 5 illustrates that power factor $\operatorname{Cos}(\theta)$ can improve to $\operatorname{Cos}\left(\theta^{\prime}\right)\left(\theta\right.$ decreased to $\left.\theta^{\prime}\right)$, while

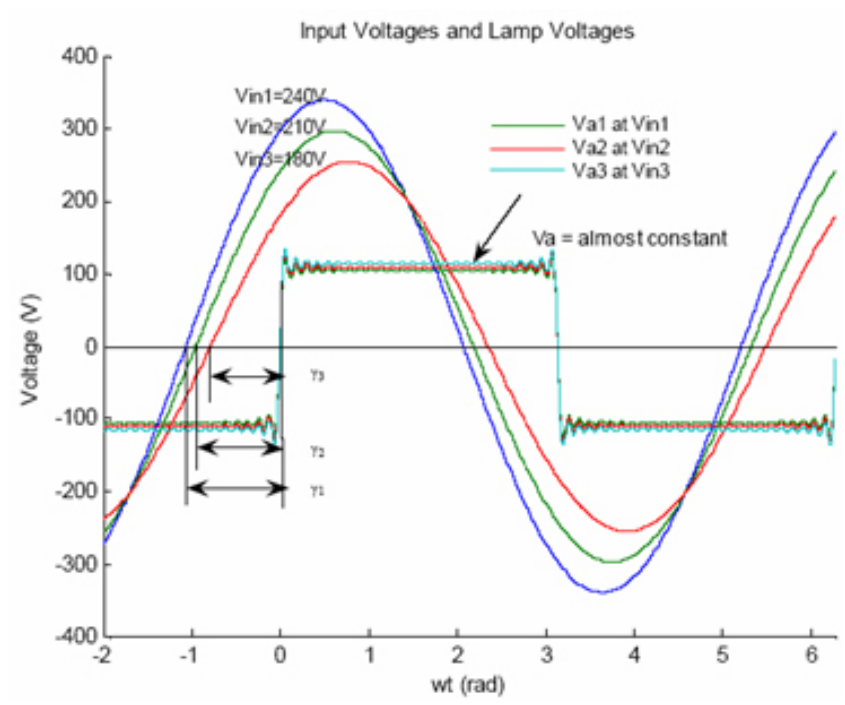

Fig. 4. Corresponding lamp voltages at different input voltages.

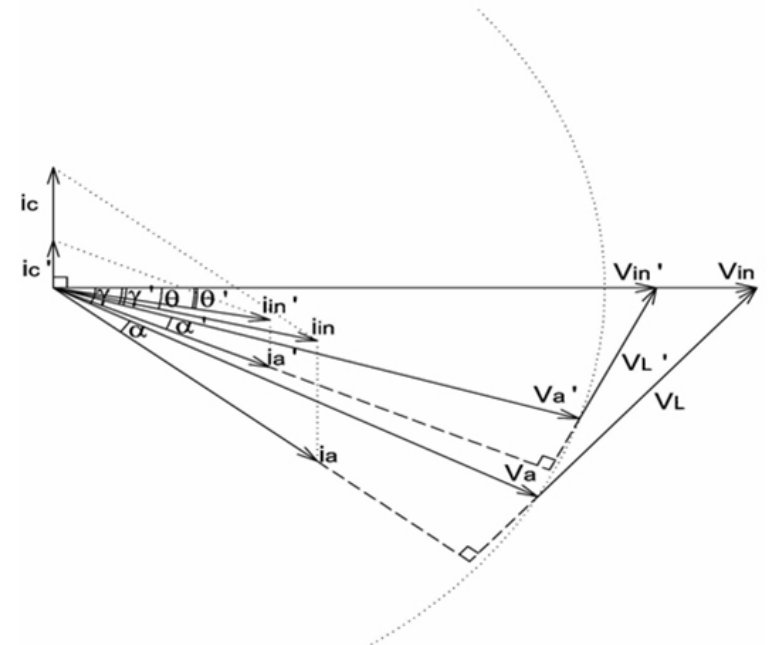

Fig. 5. Phasor diagram of power factor improvement.

the output power factor, $\operatorname{Cos}(\alpha)$ is maintained, $\left(\alpha\right.$ and $\alpha^{\prime}$ is almost the same).

Equation (4) shows that the amplitude of lamp current is directly proportional to the value of the inductor (L) [2]. The lamp current and voltages at three different input voltages $(240 \mathrm{~V}, 210 \mathrm{~V}$ and $180 \mathrm{~V})$ for the measured value of inductance $(\mathrm{L}=0.959 \mathrm{H})$ for the ballast used in the experiment was plotted in Fig. 6. The lamp current will significantly decrease with a reduction in the supply voltage. However, the lamp voltage remains nearly the same. This implies that the reduction in the power consumption in the lamp tube is a portion of the total power reduction. The input current can be derived from (7):

$$
i_{\text {in }}=i_{c}+i_{a}
$$

Where the capacitor current is

$$
i_{c}=\omega C V_{i n} \cos (\omega t+\gamma+\pi / 2)
$$

The phase shift $(\pi / 2)$ is due to the leading capacitor current over the voltage. By replacing (8) in (7), the input current can 


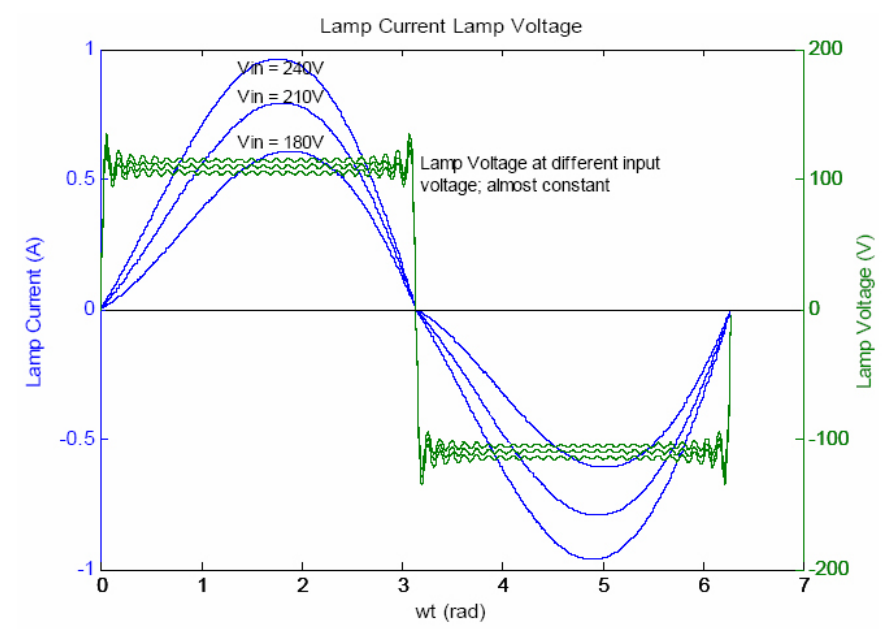

Fig. 6. Lamp current and voltages at different input voltages.

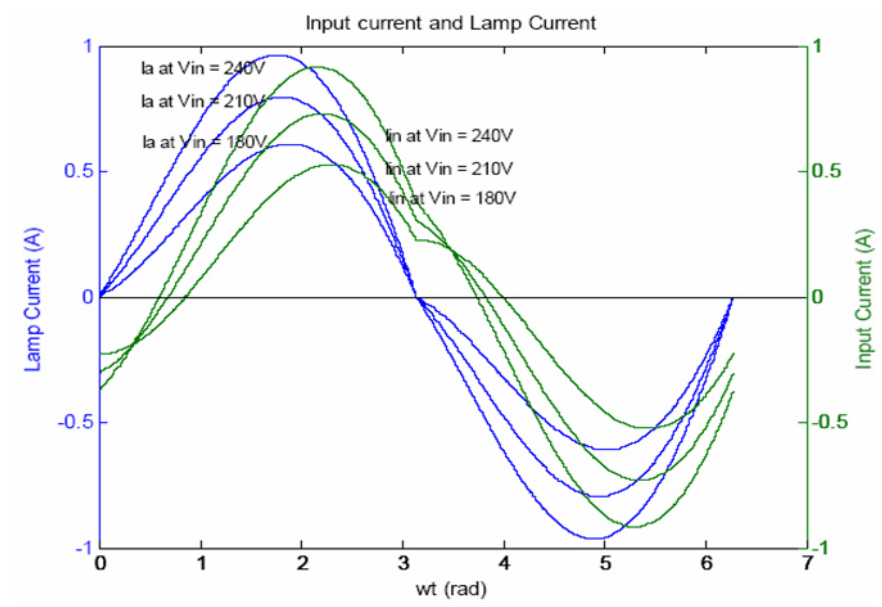

Fig. 7. Input and Output Current at different input voltages.

be expressed as (9):

$i_{i n}=\omega C V_{i n} \cos (\omega t+\gamma+\pi / 2)+\frac{V_{a}}{\omega L}\left(\frac{\pi}{2}-\omega t\right)-\frac{V_{i n}}{\omega L} \cos (\omega t+\gamma)$.

Fig. 7 shows the typical input and output currents at different input voltage levels. The plot emphasizes that as the input voltage is reduced, the input current will consequently decrease, which will result in decreasing the input power to the system.

$$
p=\frac{1}{\pi} \int_{0}^{\pi} V_{a} i_{a} d(\omega t)=\frac{2 V_{i n} V_{a}}{\omega L} \sin \gamma .
$$

The instantaneous lamp power $(\mathrm{P})$ is related to the luminous flux, $\Phi$ [18]. The lamp power (10) can be reduced as $\gamma$ is reduced by reducing the input voltage (Vin). It is important to note that although the voltage of the lamp tube remains the same, the power in the lamp tube decreases, which is directly proportional to the luminous flux. It can be inferred that this reduction is much less compared to the input power. Our aim is to find the appropriate reduced voltage such that the luminous flux, $\Phi$, will be within permissible levels.

\section{Potential for Energy Saving by Input Voltage REDUCTION}

A good lighting design should aim to save energy and provide a suitable visual environment, fulfilling the necessary conditions for occupants. In conventional lighting design the maintenance factor is considered. This is the quotient of the illuminance at the end of the maintenance interval divided by the initial luminance. It means that all lighting systems are over designed to ensure that FLs can generate minimum illuminance at the end of the maintenance interval. This allows the opportunity to save energy, especially at the beginning of the life of the lamps and can be achieved by reducing the supply voltage, which results in a reduction of power consumption.

As discussed in the last section, lamp voltage remains almost constant. However lamp current changes as a function of the supply voltage. Thus, reduction in the supply voltage results in a decrease in the input current as well as the lamp current. Consequently, power consumption decreases much more than the lamp tube's power consumption, which causes the luminous flux of a fluorescent lamp to decrease slightly. The effect on the luminous flux is found to be so small that eyesight cannot detect the change, especially if the input voltage is reduced gradually.

The Australian Standard has recommended 320 Lux for general offices [13]. General offices include areas where tasks such as typing, writing, reading and filing are performed. Despite the form of the building structure, it is recommended that this average illuminance be maintained until the end of the maintenance interval. As outlined earlier, in every proper lighting design, after including the maintenance factor for office areas, numbers of FL lamps are over designed to make sure that the lighting system can satisfy the recommended standard levels. Therefore the proposed energy saving concept should not deteriorate from these limits. Additionally, where sunlight is available in office areas, greater energy saving is possible while maintaining the minimum required lighting levels in office areas. This can be done by providing external feedback to the voltage controller in energy saving voltage controllers (ESC) via photocell sensors. Fig. 8 shows the schematic diagram of an energy saving lighting system, where the ESC is introduced to maintain the new proposed supply voltage.

The controller itself can basically be implemented by means of various types of topologies, such as an autotransformer with tap-changing or with a servo-motor, as well as electronicsswitch based voltage controller. The first approach uses a conventional controller consisting of an autotransformer with servo motor. The general principle of this controller is to maintain the output voltage variation as close as possible to the reference voltage, Vref. In a typical commercial building, the distribution board is subdivided into lighting load as well as other loads. Since the loads are so divided, they permit easy implementation of the designed controller, which will be installed with low cost under $\$ 100 / \mathrm{KW}$ between the distribution board and the lighting load. For the existing structure, updating components and installing control systems are both cost effective alternatives. Installing the proposed energy saving lighting system will not disturb any other existing components in the electrical systems of office buildings. 


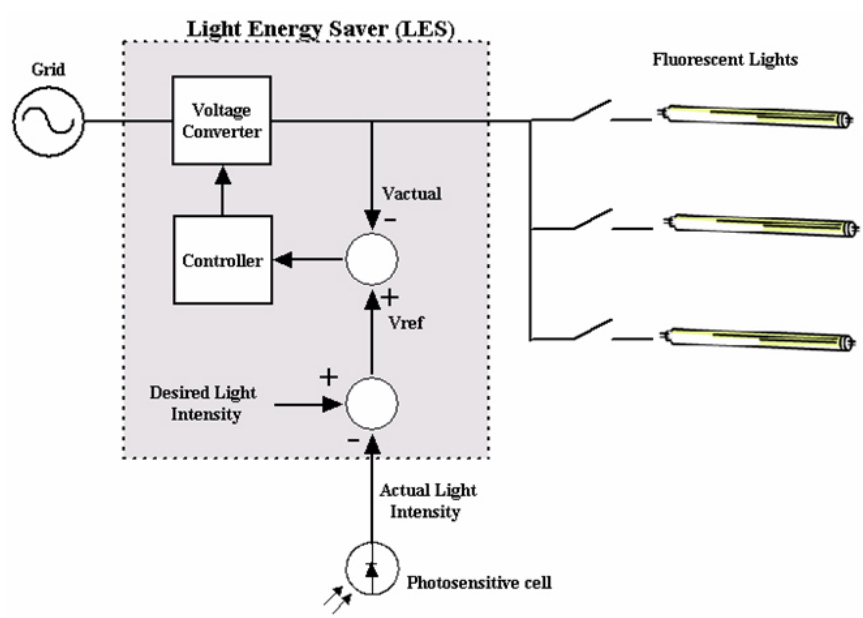

Fig. 8. Prototyped lighting energy saving controller (ESC) for FL system.

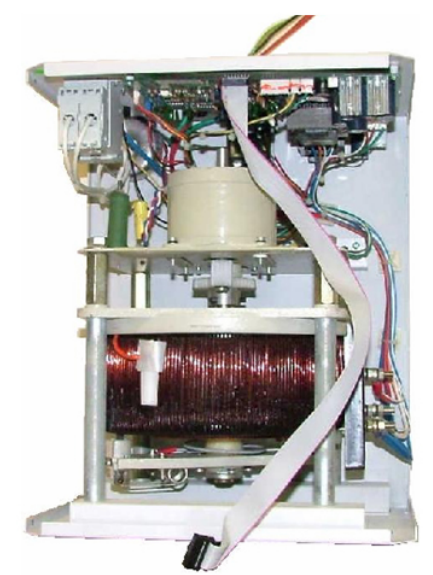

Fig. 9. Proposed lighting energy saving controller (ESC) for FL system.

\section{EXPERIMENTAL RESULTS}

\section{A. The Effect of Reducing the Input Voltage}

Experiments were conducted to verify the effects of reducing supply voltages on the electrical characteristics of fluorescent lamps. In this experiment, one fluorescent tube, a Philips (TLD 36W/33) fitted with an electromagnetic ballast was used. An autotransformer based voltage regulator was used to regulate the supply voltage from $260 \mathrm{~V}$ to $180 \mathrm{~V}$ (Fig.9). From observation, the lamp showed flickering at $175 \mathrm{~V}$. The measurements of voltage, current, active, reactive and apparent power as well as the power factor of the lamps were obtained by using a Power Quality Analyser (Fluke 43). This also displayed the voltage and current waveforms. The relative luminous flux was measured at different input voltages using a Lux meter, installed at about $1 \mathrm{~m}$ below the fluorescent lamp in a dark room. A dark room chamber $(2.85 \mathrm{~m} \times 2 \mathrm{~m} \times 3.3 \mathrm{~m})$ was built to ascertain the performance of the light output at reduced input voltage. The reference lamp and ballast was certified and the Lux meter was calibrated before the measurement. The test was performed in an air-conditioned lab with an ambient temperature of $23^{\circ} \mathrm{C}$. To prevent unstable electric and luminous characteristics, the lamp was initially allowed to warm up. The measured parameters were recorded at the selected data range, from $260 \mathrm{~V}$ to $180 \mathrm{~V}$, with a $2 \mathrm{~V}$ step. The effects of reducing the supply voltage on electrical parameters

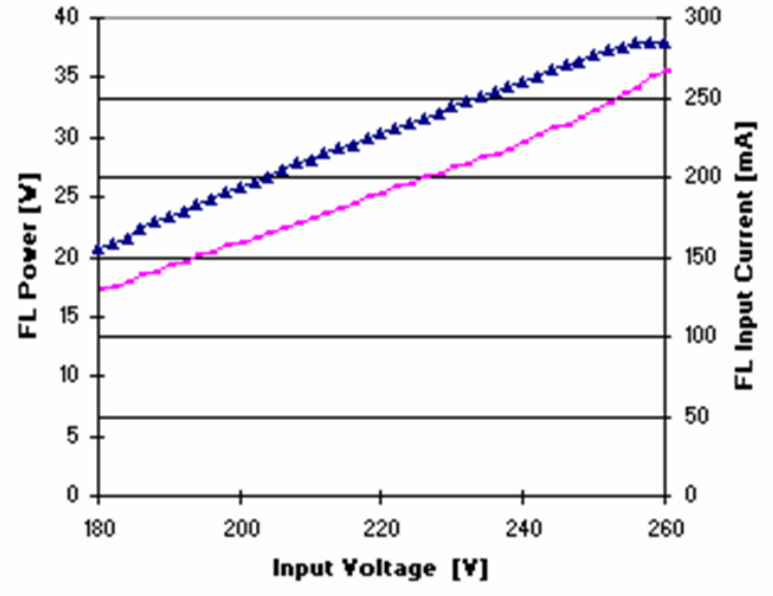

- FL Input Current [mA] $\multimap$ FL Power [W]

Fig. 10. The effect of an FL input current at different input voltages.

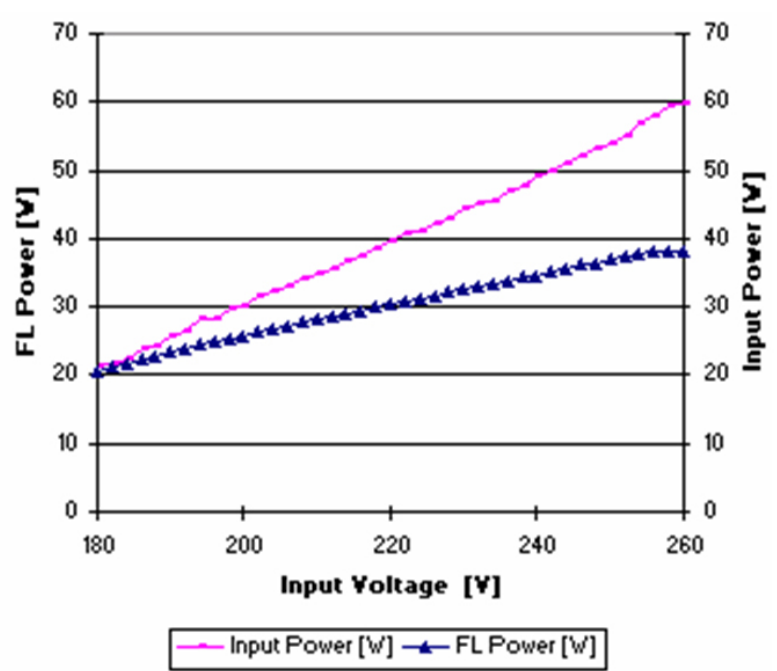

Fig. 11. The effect of Input and Lamp Power at Different Input Voltages.

are clearly shown in Fig. 10 to Fig. 14 (eg., input current, power, power factor, etc.).

Fig. 10 shows that the input current and output power from the FL has a linear relationship with input voltage changes. It can therefore be expected that more reduction in the input voltage resulted in higher input current and FL output power reduction.

Fig. 11 shows the difference between input and FL (lamp output) power with respect to different input voltages. As expected from (10), by changing the voltage from $240 \mathrm{~V}$ to $180 \mathrm{~V}(25 \%)$ the input power decreases by about $49 \%$ and the lamp power decreases only $40 \%$. Therefore, changing the input voltage has a huge impact on input power and lamp tube power consumptions. This was shown in practice by reducing the input voltage from $230 \mathrm{~V}$ to $210 \mathrm{~V}$ as much as $10 \mathrm{~W}$, with a saving of approximately $20 \%$. Considering an office area with $100036 \mathrm{~W}$ FL, the total power required should be $36 \mathrm{~kW}$. By using the proposed scheme, it is possible to save $7.2 \mathrm{kWh}$ of energy.

Fig. 12 shows the input power factor of the fluorescent lamp under variations of input voltage. From the graph shown, it appears that the power factor has improved from 0.92 at $230 \mathrm{~V}$ 


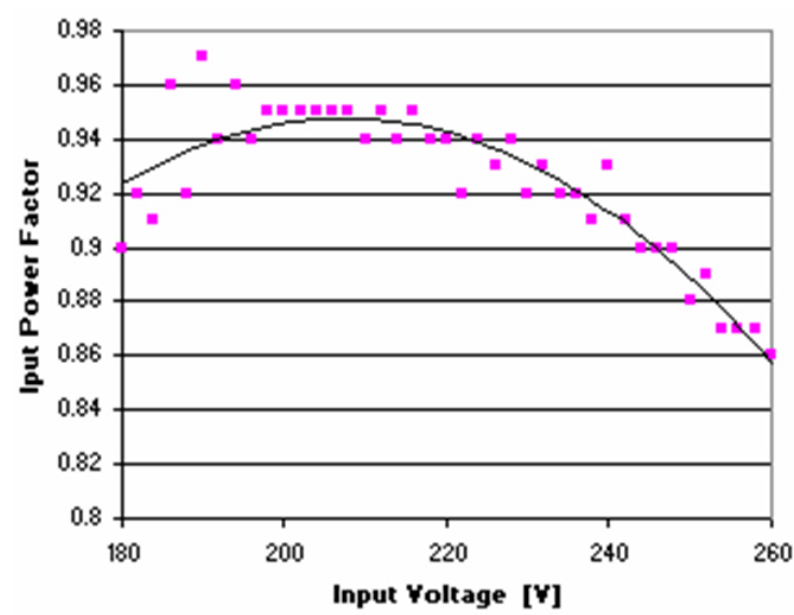

Fig. 12. Power Factor at Different Input Voltages.

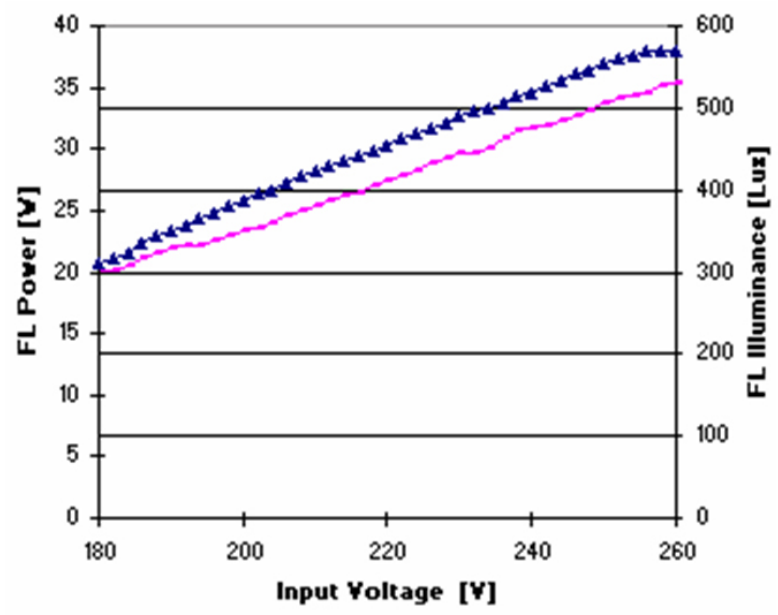

- FL Illuminance [Lux] $\leftarrow$ FL Power [W]

Fig. 13. Relative Illuminance at different Input Voltages.

to 0.95 at $210 \mathrm{~V}$ as the input voltage is reduced. Working in this voltage range can thus improve the power factor slightly, which alone can contribute to further improvement. This result confirms the analytical modelling simulation, where it was predicted that the power factor would improve for lower input voltages (Fig. 5).

Fig. 13 shows the dependency of the light outputs' power and illuminance to different input voltages. As expected these two curves are very proportionally linear, however at lower voltage, lower power resulted in higher illuminance. From the graph, the illuminance difference at $230 \mathrm{~V}$ and $210 \mathrm{~V}$ is as much as 65 Lux.

Fig. 14 illustrates the performance of the FLs at different input voltages. This test shows that by reducing the voltage of the lamp the FLs perform better. Hence, voltage reduction could lead inherently to higher FL performance.

\section{B. Performance Analysis in Office Buildings}

To verify the effectiveness of the energy saving controller, a comprehensive experiment was carried out on an office area consisting of 40x36W FLs (total $1.4 \mathrm{~kW}$ ). The prototyped ESC was used in the office area to control the input voltage to the FL lightings. It was recorded that when the ESC reduced the

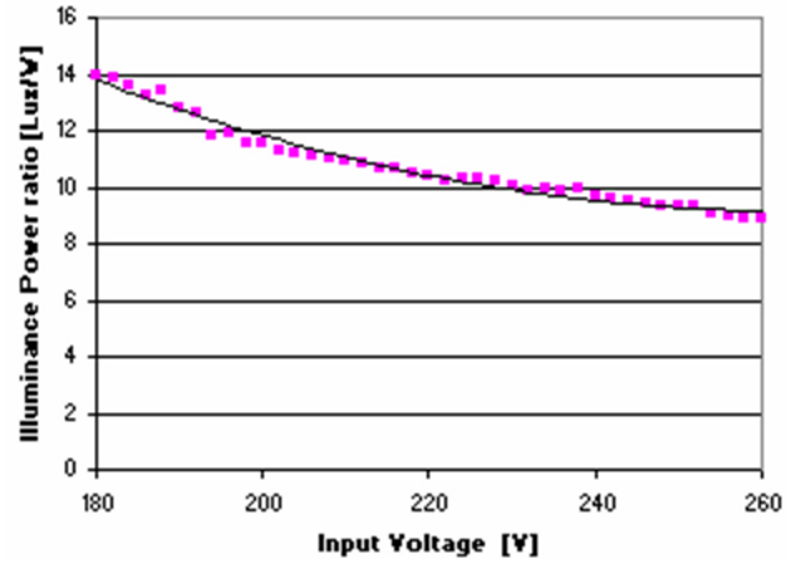

Fig. 14. Illuminance Power Ratio at Different Input Voltages.

input voltage from 246 to $210 \mathrm{~V}$ to supply the $40 \mathrm{FLs}$, the input power changed from $1.88 \mathrm{~kW}$ to $1.33 \mathrm{~kW}$. This means that the saving in electricity consumption was about $0.55 \mathrm{kWh}$ per hour (approximately 30\%).

The office was blinded by curtains, so that daylight would not affect the results. Two different locations in the office were selected to record the illuminance. In the first position (near to the fax machine), the lux meter showed $363 \mathrm{Lux}$ and in the second position (one of the office desks), 330 Lux was recorded at normal grid voltage $(243 \mathrm{~V})$. The current and voltage of the FLs when the ESC is bypassed is shown in Fig. 15(a), (the lighting system is connected directly to the grid). After activating the ESC the input voltage to the FLs was reduced to $206 \mathrm{~V}$ (Fig. 16(a)). The distortion in the current of the FLs can be explained by the actual arcing in the lamp tubes. Due to the existence of the inductor (operating the same as the decoupling inductor) the input voltage to the FL remains sinusoidal. As was expected the current in the lamps drop with the decrease in input voltage. After a decrease in the input voltage to FLs, the illuminance reading had shown the reduction to 291 Lux for the first location and 265 Lux for the second location in the office area. Due to lack of feedback in the system, the illuminance dropped under the limit $(320$ Lux). However, the ESC with feedback control guarantees that the illuminance never drops under the recommended limits under any condition. Moreover, the feedback from the actual illuminance of the area can improve the performance of the lighting system as well as maximize the energy savings in the office area using the available daylight illuminance.

\section{Harmonic performance}

To evaluate the harmonic performance of the FLs under reduction of the input voltage, the FFT result of the input current was obtained (Fig. 15(b) and Fig. 16(b)). These two pictures illustrate that reduction in the input voltage does not affect the harmonic pattern and only reduces the magnitude of the harmonics. There the THD remains almost the same. This was also confirmed by improving the power factor.

\section{CONCLUSION}

This study shows that possible effective energy saving exists for FLs in any commercial and industrial buildings. The energy 


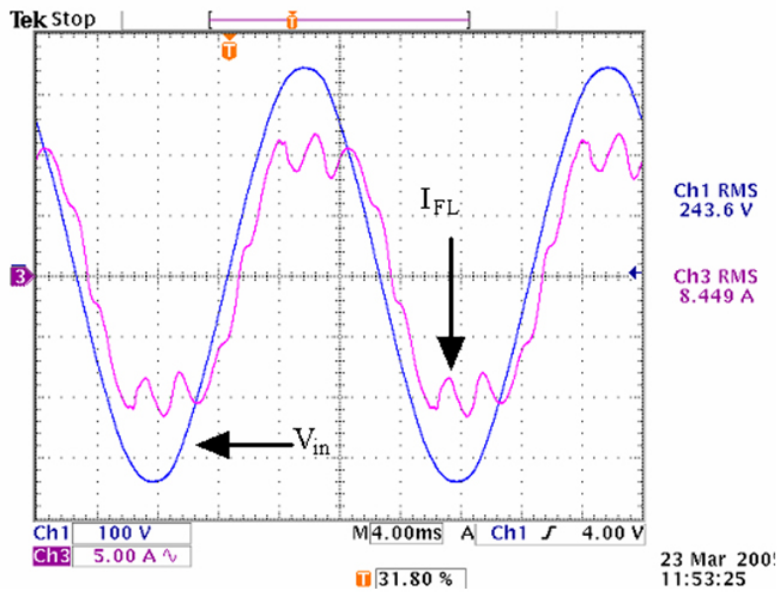

(a)

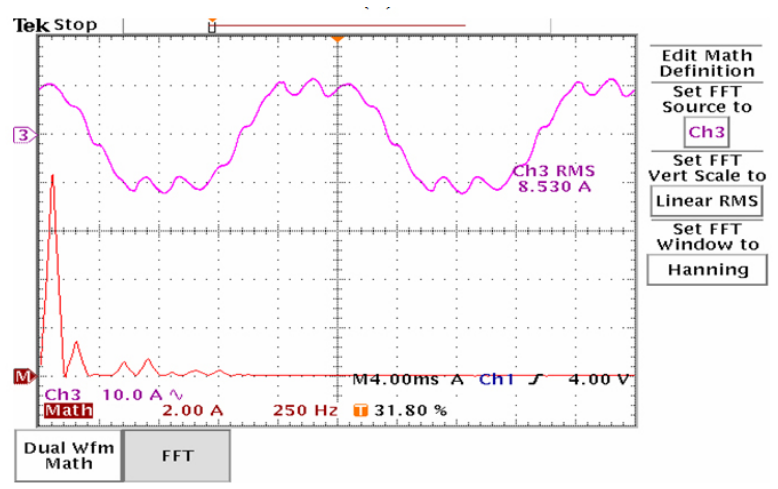

(b)

Fig. 15. FLs connect directly to the grid. (a) Input (grid) voltage and fluorescent lamps current. (b) Input current FFT result.

used for lighting in a typical office building can be reduced by as much as $20 \%$ through a simple and cost effective approach (input voltage reduction). Comprehensive study of the actual office building system with $1.44 \mathrm{~kW}$ lighting load from this research confirms the validity of the proposed concept. It is shown that an ESC may save a considerable amount of energy. The lamp illuminance power ratio also improves. This means that the efficiency of the lamp increases while using ESC. In addition, the operation of the ESC not only does not change the harmonic pattern of the FLs, but also improves the power factor. The detailed analysis and simulation with experimental evaluation confirms the effectiveness of the proposed concept which provides a very cost effective and simple lighting energy saving solution.

\section{ACKNOWLEDGMENT}

This work was partly supported by the Research \& Development Grant of the Jeollabuk-do Province, Korea. Furthermore, the authors appreciate Dr. Hooman Dehbonei and Ms Salmiah Ahmad for conducting experimental part of the investigation.

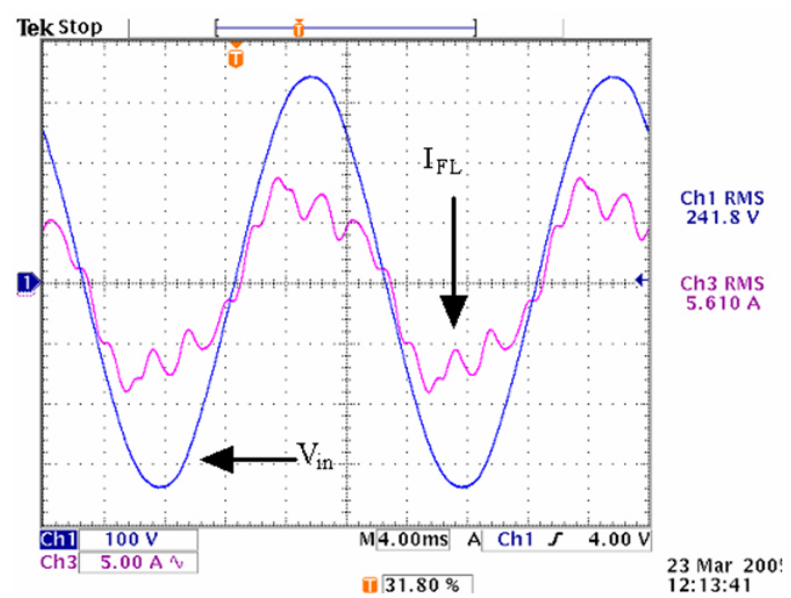

(a)

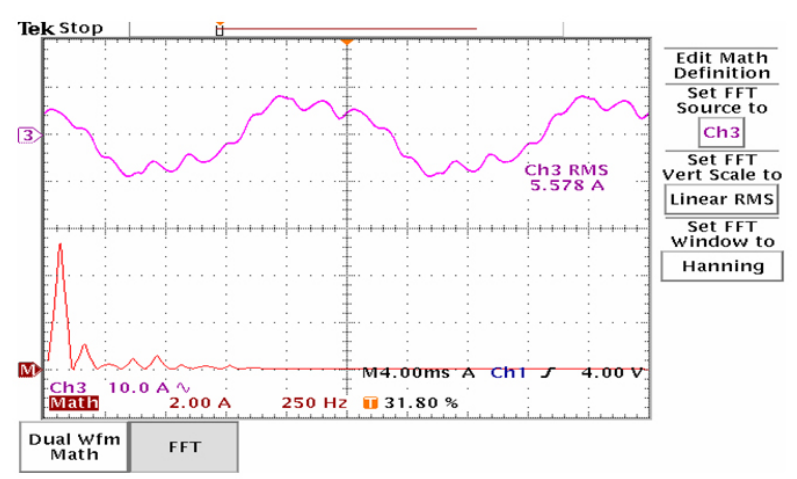

(b)

Fig. 16. FLs connect to the grid through the ESC. (a) Input (grid) voltage and fluorescent lamps current. (b) Input current FFT result.

\section{REFERENCES}

[1] A. Q. Haideri and J. A. Paraskiewicz, "Saving energy and protecting the environment through a retrofit lighting program," presented at Petroleum and Chemical Industry Conference, pp. 139-145, 1993.

[2] E. Gluskin, "Fluorescent lamp circuit," IEEE Trans. Circuits Syst. I, Fundam. Theory Appl., Vol. 46, No. 5, pp. 529-544, May 1999.

[3] D. J. Pileggi, E. M. Gulachenski, C. E. Root, T. J. Gentile, and A. E. Emanuel, "The effect of modern compact fluorescent lights on voltage distortion," IEEE Trans. Power Del., Vol. 8, No. 3, pp. 1451-1459, Jul. 1993.

[4] S. Qureshi, M. Akmal and R. Arif, "Power quality based comparison of compact fluorescent lamp with fluorescent light," Third International Conference on Electrical Engineering, pp. 1-6, 2009.

[5] H. Shareef, A. Mohamed and K. Mohamed, "Development of Voltage Acceptability Curves for Fluorescent Lighting Systems," International Conference on Electrical Engineering and Informatics, Vol. 02, pp. 513518, 2009.

[6] G. W. Chang, S. K. Chen, and G. Chen, "Harmonic-domain modeling of fluorescent lamp with electromagnetic ballast," presented at IEEE Power Engineering Society Summer Meeting, Vol. 1, pp. 267-270, 2001.

[7] E. Gluskin, "High harmonic currents in fluorescent lamp circuits," IEEE Trans. Industry Appl., Vol. 26, No. 2, pp. 347-351, Mar./Apr. 1990.

[8] F. V. Topalis, "Efficiency of energy saving lamps and harmonic distortion in distribution systems," IEEE Trans. Power Del., Vol. 8, No. 4, pp. 2038-2042, Oct. 1993.

[9] A. E. Emanuel and L. Peretto, "The response of fluorescent lamp with magnetic ballast to voltage distortion," IEEE Trans. Power Del., Vol. 12, No. 1, pp. 289-295, Jan. 1997.

[10] C.-M. Fu and M.-T. Chen, "The characteristics of fluorescent lamps under problematic utility voltage," presented at Energy Management and Power Delivery, Proceedings of EMPD '95, Vol. 1, pp. 140-145, 1995.

[11] A. Trostl, "Self configuring dimming interface for fluorescent lamp ballasts," presented at IEEE Thirty-Sixth IAS Annual Meeting on Industry Applications Conference, Vol. 2, pp. 9026-911, 2001. 
[12] F. Rubinstein, M. Siminovitch, and R. Verderber, "Fifty percent energy savings with automatic lighting controls," IEEE Trans. Ind. Appl., Vol. 29, No. 4, pp. 768-773, Jul./Aug. 1993.

[13] S. AustraliaTM, "AS 1680.1-1990 "Interior lighting: Part 1: General principles and recommendation"," in Standards AustraliaTM, 1990.

[14] Standards AustraliaTM, "AS 1680.4-2001 "Interior lighting: Part 4 Maintenance of Electric Lighting Systems"," in Standards AustraliaTM, 2001.

[15] E. Deng and S. Cuk, "Negative incremental impedance and stability of fluorescent lamps," presented at APEC Twelfth Annual Conference Proceedings on Applied Power Electronics, Vol. 2, pp. 1050-1056, 1997.

[16] E. Gluskin, "Discussion of the voltage/current characteristic of a fluorescent lamp," IEE Proc. on Science, Measurement and Technology, Vl. 136, pp. 229-232, 1989.

[17] G. W. Chang, "Characterizing harmonic currents generated by fluorescent lamps in harmonic domain," IEEE Trans. Power Del. Vol. 18, No. 4, pp. 1583-1585, Oct. 2003.

[18] G. C. Montanari and L. Peretto, "A model for fluorescent lamp flicker in the presence of voltage distortion," presented at Proc. of 8th International Conference on Harmonics and Quality of Power, Vol. 2, pp. 1206-1210, 1998.

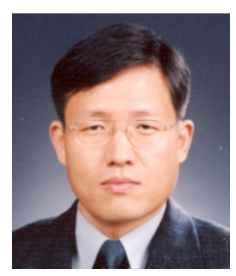

Seong-Ryong Lee received his B.Sc. and M.S.c degrees in Electrical Engineering from Myong-Ji University Seoul, Korea in 1980 and 1982, respectively, and his Ph.D. degree from Chonbuk National University, Jeonju, Korea, in 1988. From 1997 to 1998, he was a Visiting Professor with the Department of Electrical and Computer Engineering at Virginia Tech, VA. From 2002 to 2004, he was a Director of Engineering Research Institute at Kunsan National University, Kunsan, Korea.
From 2004 to 2006 he was a Visiting Professor with the Department of Electrical and Computer Engineering at Curtin University of Technology, Perth, Australia. From 2009 to 2011, he was a Dean of college of Engineering at Kunsan National University, Kunsan, Korea. Since 1990, he is a professor with the Dept. of Control and Robot Engineering at Kunsan National University. His current research interests include soft-switching inverter, power factor correction, switch mode power supply, and renewable energy based distributed generation system.

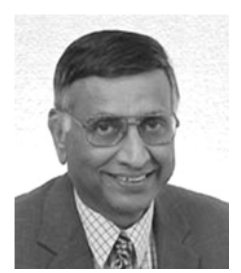

Chemmangot V. Nayar received his B.Sc in Electrical Engineering from the University of Kerala, India in 1969, his Master of Technology degree in Electronics from the Indian Institute of Technology, Kanpur in 1976 and his $\mathrm{PhD}$ in Electrical Engineering specializing in wind electrical power generation from the University of Western Australia in 1985. Prior to joining the School of Electrical and Computer Engineering at Curtin University of Technology, Perth, Australia, in 1986, he held academic and industry appointments in India, Singapore and Australia. $\mathrm{He}$ holds a personal chair in Electrical Engineering and is the Managing Director of Regen Power Pty Ltd based in Perth, Sydney and Brisbane in Australia. In 1988 he established the Centre for Renewable Energy and Sustainable Technologies Australia at Curtain University and successfully managed the centre for 15 years while undertaking extensive research on wind, solar and hybrid systems, both in Australia and internationally. He has authored or coauthored more than 90 refereed journal articles, several book chapters and over 120 conference presentations. He is a chartered professional engineer and a Fellow of the Institute of Engineers Australia, a Chartered Engineer and Member of the Institute of Electrical Engineers (UK) and a Senior Member of the Institute of Electrical and Electronic Engineers (USA) 